\title{
Clinical Performance Analysis and Evaluation of Quantitative Real Time PCR for Diagnosis of Scrub Typhus in North East India
}

By - Diptanu Paul ${ }^{1}$, W Valarie Lyngdoh*, Himesh Barman, Clarissa Jane Lyngdoh, Kryshanlang Lynrah, Elantamilan Durairaj

\section{North Eastern Indira Gandhi Regional Institute of Health and Medical Sciences}

Correspondence to:

W Valarie Lyngdoh

Department of Microbiology, NEIGRIHMS, Shillong, Meghalaya, India. Pin- 793018.

Phone - +918837462966/ +919862079610

Email: drval@ rediffmail.com

\begin{abstract}
Scrub typhus being a life threatening infectious disease and always creating diagnostic dilemma in terms of rapid turnaround time and accuracy, qRT PCR can become a very good option to achieve the desired result with molecular level of accuracy and boost up the rapid patient management. This study was performed to evaluate the performance of qRT PCR in comparison to commonly used IgM ELISA and Weil-Felix tests to diagnose scrub typhus, as well as to look for the demographic and clinical profile of the disease in North-East India. It was a hospital-based prospective study conducted in a tertiary care hospital of north-east India, over a period of 1 year, in which all the samples from suspected scrub typhus cases were screened by Weil-Felix test as per institute's diagnostic protocol after which IgM ELISA for Scrub Typhus was performed. All the IgM positive samples and 20 highly suspected but ELISA negative samples were subjected to qRT PCR, targeting $56 \mathrm{kDa}$ type specific gene of $O$. tsutsugamushi. Statistical analysis was done by MS-Excel for Windows v2013® and MedCalc ${ }^{\circledR}$ v17.9 for Windows (MedCalc Software, Acacialaan 22, B-8400 Ostend, Belgium). In this study we have successfully evaluated the performance of qRT PCR kit for diagnosis of scrub typhus. Out of 54 samples tested, 24 IgM ELISA positive samples and 3 IgM ELISA negative samples have shown the presence of bacterial DNA with quantification of DNA copies. It has also been observed that 21 out of 27 PCR positive samples (77.8\%) were detected within the $1^{\text {st }} 7$ days of illness. All the demographic as well as clinical data were also analysed. The performance of the commercial qRT PCR kit used in our study is satisfactory, which provides extra advantage of quantification of DNA copies and increases diagnostic accuracy within the $1^{\text {st }}$ week of fever.
\end{abstract}

\section{KEYWORDS}

Scrub typhus; qRT PCR; Quantitative PCR; real time PCR; IgM ELISA; North-East India 


\section{INTRODUCTION}

Scrub typhus is a life-threatening infectious disease, which represents a good share of acute undifferentiated fever mainly in the tropical region. The term "Scrub" was used due to the vegetarian terrain in which the vector - trombiculid mites reside and the word "Typhos" means 'stupor caused by a fever' in Greek[1,2].

The World Health Organization has already named scrub typhus as one of the world's most underdiagnosed/underreported disease which often warrants hospital admission due to acute febrile illness along with multi-organ failure[3]. Scrub Typhus is creating havoc in different parts of the country, especially in the sub-Himalayan region. The disease is highly endemic in an imaginary area called "Tsutsugamushi Triangle", however recent studies and reports have indicated regions of emerging and new areas outside of the "Tsutsugamushi Triangle"[4-6].

Scrub typhus is prevalent in many parts of India, but specific data is not available. However, there are documented outbreaks in areas located in the sub-Himalayan belt. Few major outbreaks were reported from Tamil Nadu, Karnataka, Pondicherry, Manipur, Meghalaya, Assam, West Bengal and other North-eastern states of India[7,8]. In North-Eastern states of India like Assam there is re-emergence of scrub typhus after a gap of 65 years[2]. North-Eastern states of India are also known to be the abode of its misery due to nature's curse in blessings.

The causative agent of Scrub typhus, Orientia tsutsugamushi. is a gram negative obligately intracytosolic bacterium which belongs to family Rickettsiaceae, genus Orientia (formerly, Rickettsia) and species tsutsugamushi[1]. Scrub typhus is transmitted to humans and rodents by some species of trombiculid mites ("chiggers", Leptotrombidium deliense and others). However, another new mite species, Schoengastiella ligula, in the same superfamily Trombiculoidea, but within the family Walchiidae, has also been implicated as a vector[9]. The adult mites have a four-stage lifecycle: egg, larva, nymph, and adult. The larva is the only stage (chigger) that can transmit the disease to humans and other vertebrates, since the other life stages (nymph and adult) do not feed on vertebrate animals[10]. Chigger bite is usually painless, usually found around the groin, axillae, genitalia, or neck resulting into an eschar formation. Eschar is pathognomonic for scrub typhus but may not be found in all the patients. The clinical manifestations of this disease ranges from subclinical disease to organ failure leading to death. Patients usually presents with fever, rash, headache, myalgia and diffuse lymphadenopathy[11]. Mortality rate in untreated patients ranges from 0-30\% depending upon the geographic area, the prevalent strain and the time of intervention taken.

Scrub typhus is grossly under-diagnosed in India due to its non-specific clinical presentations, limited awareness, and low index of suspicion among physicians. Differentiating scrub typhus from other forms of typhus as well as from other causes of acute fever like - sepsis, malaria, dengue, typhoid, and meningococcal infections is often difficult during the first several days due to vague clinical presentations. The most common signs and symptoms are similar to a variety of other infectious diseases which should be taken into consideration[12].

The mainstay of diagnosis of scrub typhus is serological testing, which also can be used in epidemiological studies of the disease. Few cases have been tested positive for IgM antibodies for scrub typhus in Sikkim, Darjeeling, Nagaland, and Manipur. In Meghalaya, where this 
study was conducted, this disease is known to be endemic, responsible for significant amount of mortality and morbidity every year[13-15].

Isolation of the organism from blood is laborious and time-consuming process as it takes more than a month using cell culture. Nonspecific Weil-Felix test is extensively used everywhere but it lacks in both sensitivity and specificity. The presence of scrub typhus based on this nonspecific Weil-Felix test, had been documented in Jammu and Kashmir, Himachal Pradesh, Uttaranchal, Rajasthan, Assam, West Bengal, Maharashtra, Puducherry, Kerala and Tamil $\mathrm{Nadu}[16,17]$. Immunochromatographic card test is also a very popularly used tool, which also lacks in specificity. The Immunofluorescence antibody assay (IFA) has subsequently replaced the Weil-Felix assay as a "Gold Standard" test for the detection of antibodies induced by Orientia[18]. However, the lack of standardization of IFA assays among laboratories around the world has brought into question, its applicability in the diagnosis of scrub typhus[19]. A more standardized methodology is the ELISA, which has been used for years in surveillance studies, where large number of sera can be assayed at one time.

The utilization of molecular methods in the past 20 years have increased the sensitivity and specificity of diagnosis of scrub typhus and other rickettsial diseases along with their detection in vertebrate hosts and invertebrate vectors[20]. Recent nucleic acid-based techniques like conventional PCR, nested PCR and Real time PCR are useful for early and specific diagnosis.

Because of the low index of suspicion, nonspecific signs and symptoms, emergence in nonendemic areas as well as re-emergence in previously endemic areas and absence of widely available sensitive and specific diagnostic tests, Scrub typhus is really imposing a diagnostic challenge.

Hence, this study was planned to evaluate the diagnostic performance of quantitative real time PCR to detect the presence of Orientia tsutsugamushi in patients with febrile illness, presenting to a tertiary care hospital of North-East India, where Scrub-Typhus is highly endemic.

\section{MATERIALS AND METHODS}

Study design - This was a hospital based prospective study conducted in the Department of Microbiology, of a tertiary care center of North-East India over a period of 1 year (June 2016 - May 2017).

\section{Inclusion Criteria -}

Case - Patients are included in the study if they have -

1) Febrile illness (fever $>37.8^{\circ} \mathrm{C}$ ) and a clinical suspicion of scrub typhus, presenting to the department of Medicine and Pediatrics.

2) Given written informed consent to participate in the study, either by themselves or by parents/guardians (for pediatric age group).

Controls - Twenty volunteers with no history of fever and no history of scrub typhus before, otherwise healthy were also included in the study as controls. 
Exclusion Criteria - Patients were excluded if a definitive diagnosis of malaria, enteric fever, tuberculosis, any other infectious or non-infectious etiology was made during patient work-up.

Sample size - One hundred patients with acute febrile illness, without any definitive diagnosis and clinical suspicion of scrub typhus were included in the study.

Ethical approval - Ethical approval was taken from the institution Ethics Committee, letter no. -NEIGR/IEC/2015/0040.

History taking and Sample collection - A detailed history taking of all the patients along with physical examination was performed. All the patients were further followed up for their clinical progression and outcome.

Blood samples were collected in plain vacutainers (without anticoagulant) from 100 patients of acute febrile illness (cases) and from 20 healthy volunteers (controls), taking both inclusion and exclusion criteria under consideration.

Samples were further processed and analyzed for the detection of Orientia tsutsugamushi.

Collection of serum samples and storage - Serum had been collected from plain vials clotted blood after centrifuging at 2000 RPM for 10 minutes and then separating serum without touching the leukocyte layer.

Aliquots were made from serum samples into 3 parts for different purposes.

$\underline{\text { Part } 1}$ - For screening by Weil-Felix test.

$\underline{\text { Part } 2}$ - For doing ELISA to detect IgM against Orientia tsutsugamushi.

$\underline{\text { Part } 3}$ - For DNA extraction from the serum samples and PCR.

Part 2 and 3 of aliquots were stored at 2 to $8^{\circ} \mathrm{C}$ for 48 hours, then at $-20^{\circ} \mathrm{C}$ for 1 month and for further storage of $>1$-month aliquots were stored at $-80^{\circ} \mathrm{C}$.

Screening by Weil-Felix test - All the serum samples were screened first for scrub typhus by using Weil-Felix test. "PROGEN" Proteus antigen suspensions by Tulip Diagnostics (P) LTD. India, were used for Weil-Felix test by semi-quantitative slide method following the exact manufacturer's instructions and titers of OXK antigen were obtained.

IgM ELISA - "Scrub Typhus Detect ${ }^{\mathrm{TM}}$ IgM ELISA System" by INBIOS International, Inc. was used for performing ELISA to detect IgM antibodies against Orientia tsutsugamushi derived recombinant antigen in stored serum samples.

ELISA procedure - All the serum samples from 20 healthy volunteers and all the 100 stored serum samples from suspected scrub typhus patients were subjected to IgM ELISA for scrub typhus following the manufacturer's instructions exactly. All the ELISA readings were obtained by using "Merilyzer EIAQuant Microplate Reader" - by Meril Life Sciences.

Cut-off calculation - Cut off was calculated as per manufacturer's instructions by adding the mean of OD plus three times of the Standard Deviation (SD) of normal human serum. Serum samples from 20 healthy volunteers were used to calculate the cut-off. The mean and SD of all 
healthy volunteers corresponded to OD values of 0.1445 and 0.0437 , respectively. Using the manufacturer's cutoff formula of the final ELISA cutoff corresponded to an OD of 0.2756.

Interpretation of the results were done by following the below mentioned criteria -

1. Samples with spectrophotometric readings > Cut off are "Reactive" and samples below this criterion are considered to be "Non-Reactive".

2. Values near the Cut off are doubtful and the assays were repeated

DNA extraction - From all the IgM ELISA reactive samples as well as 20 highly suspected but ELISA negative samples DNA was extracted using “QIAamp DNA Mini Kit”" (Qiagen, Germany) as per the manufacturers' instructions. Extracted DNA samples were kept frozen at $-80^{\circ} \mathrm{C}$ till the time of testing.

Real time Polymerase Chain Reaction - Extracted DNA samples were subjected to quantitative real-time PCR by using “Geno-Sen's Scrub Typhus (Rotor Gene) real time PCR kit”, Genome Diagnostics Pvt. Ltd, Solan, Himachal Pradesh, India.

\section{Principle of Real-Time PCR kit used -}

The kit targets $56 \mathrm{kDa}$ Type Specific gene of O. tsutsugamushi. The robust assay exploits the so-called TaqMan principle. During PCR, forward and reverse primers hybridize to a specific sequence product. A TaqMan probe, which is contained in the same reaction mixture and which consists of an oligonucleotide labeled with a 5'-reporter dye and a downstream, 3'-quencher dye, hybridizes to a target sequence within the PCR product. A Taq polymerase which possesses 5' - 3' exonuclease activity cleaves the probe. The reporter dye and quencher dye are separated upon cleavage, resulting in an increase in fluorescence for the reporter. Thus, the increase in fluorescence is directly proportional to the target amplification during PCR.

The primer details are as follows:

- OtsuF: 5'-AATTGCTAGTGCAATGTCTG-3',

- OtsuR: 5'-GGCATTATAGTAGGCTGAG-3'

- Accession no: KP334159.1

Procedure -

a) Preparation for PCR amplification - First cooling block was pre-cooled to $+4^{\circ} \mathrm{C}$ in a Refrigerator or Deep Freezer. Desired number of PCR tubes kept into the Cooling Block. To generate standard curves, all supplied Standards (SCRUB TYPHUS S1 - S5) along with negative control (Molecular Grade Water) were used for each PCR run according to the manufacturer's instructions. Before each use, all reagents were thawed completely and mixed by pipetting or by brief vortexing. 
b) Preparation of PCR reaction mixture - For each reaction below mentioned scheme was followed as per manufacturer's instruction: -

\begin{tabular}{|l|l|}
\hline $\begin{array}{l}\text { SCRUB TYPHUS } \\
\text { MASTER MIX }\end{array}$ & Amount to be mixed per reaction \\
\hline SCRUB TYPHUS Super Mix (R1) & $12 \mu \mathrm{L}$ \\
\hline SCRUB TYPHUS Mg Sol. (R2) & $2.5 \mu \mathrm{L}$ \\
\hline IC-1 (R3) RG & $0.5 \mu \mathrm{L}$ \\
\hline Total & $\mathbf{1 5} \boldsymbol{\mu L}$ \\
\hline
\end{tabular}

$15 \mu 1$ of the Master Mix/Premix was pipetted into each labelled PCR tube. Then $10 \mu 1$ of the earlier extracted DNA was added to each sample tube and mixed well by pipetting up and down. Correspondingly, $10 \mu \mathrm{l}$ of the Standards (SCRUB TYPHUS S1-5) was added as a positive control and $10 \mu \mathrm{l}$ of water (Water, PCR grade) as a negative control. PCR tubes were closed and transferred the tubes into the rotor of the RotorGene ${ }^{\mathrm{TM}} \mathrm{Q}$ (QIAGEN Real-time PCR Cycler). Locking Ring was placed on top of the rotor to prevent accidental opening of the tubes during the run.

Then PCR run was started following the optimum cycling conditions mentioned below as per the manufacturer's instructions.

\begin{tabular}{|l|l|}
\hline Cycle & Cycle Point \\
\hline Hold & (Initiation): $95^{\circ} \mathrm{C}$ for 10 minutes \\
\hline Cycling (45 repeats) & Step 1 (Denaturation): $95^{\circ} \mathrm{C}$ for 15 seconds \\
\cline { 2 - 2 } & Step 2 (Annealing): $55^{\circ} \mathrm{C}$ for 20 seconds \\
\cline { 2 - 2 } & Step 3 (Extension): $72^{\circ} \mathrm{C}$ for 15 seconds \\
\hline
\end{tabular}

Other instructions for ideal PCR run condition were followed exactly as mentioned in the user manual provided with the PCR kit.

Quantitation -

The quantitation standards provided in the kit (SCRUB TYPHUS S 1-5) has been treated in the same way as extracted samples and the same volume is used i.e. $(10 \mu 1)$ instead of the sample. To generate a standard curve in the RotorGene ${ }^{\mathrm{TM}} \mathrm{Q}$ system, all 5 Standards were used as defined in the menu window Edit Samples of the RotorGene ${ }^{\mathrm{TM}}$ software. The standard curves generated were used for quantitation in subsequent runs, provided that at least one standard was used in the current run.

The standards are defined as copies/ $\mu$. The following formula can be applied to convert the values determined using the standard curve into copies $/ \mathrm{ml}$ of sample material: 


\section{Result (Copies/ $\mu \mathrm{l}) \times$ Elution Volume $(\mu \mathrm{l})$}

Result $($ Copies $/ \mathrm{ml})=$

\section{Sample Volume (ml)}

In our study direct conversion formula was used as the starting volume of the sample while using the Qiagen QIAamp DNA Mini extraction kit was $200 \mu 1 \&$ the final Eluted Volume was $50 \mu 1$.

Following values for the standards was fed directly into the operating software which was again based on the above formula and yielded direct conversion of per $\mathrm{ml}$ of patient sample data.

S1: $10^{5}$ Copies $/ \mu 1=25000000$ Copies $/ \mathrm{ml}$

S2: $10^{4}$ Copies $/ \mu \mathrm{l}=2500000$ Copies $/ \mathrm{ml}$

S3: $10^{3}$ Copies $/ \mu \mathrm{l}=250000$ Copies $/ \mathrm{ml}$

S4: $10^{2}$ Copies $/ \mu 1=25000$ Copies $/ \mathrm{ml}$

S5: $10^{1}$ Copies $/ \mu 1=2500$ Copies $/ \mathrm{ml}$

Statistical analysis - The data was collected and recorded using MS-Excel for Windows $v 2013 \AA$. The basic descriptive statistics, frequency charts graphs, trend analysis and related graphs were computed using the same. Summary statistics and ROC curve analysis were done using MedCalc ${ }^{\circledR}$ v17.9 for Windows (MedCalc Software, Acacialaan 22, B-8400 Ostend, Belgium). The comparison of single and two proportions were done using Chi-square test. The threshold for significance was considered at $\mathrm{p}<0.05$.

The data analysis and generation of graphs for the PCR was performed using Rotor-Gene Q Series software v2.3.1 (Build 49).

\section{RESULTS}

During the study period of one year 100 patients with febrile illness were evaluated for scrub typhus (ST). The study was conducted not only to evaluate the performance of Quantitative Real-Time (qRT) PCR as an accurate and quick diagnostic procedure for ST but also to find out different etiologies of febrile illness cases other than ST. All the collected serum samples were subjected to Weil-Felix for the screening and IgM ELISA for confirmation of ST. All the IgM ELISA positive samples and 20 highly clinically suspected samples which were IgM ELISA negative were subjected to qRT PCR. Based on IgM ELISA and PCR findings 37 patients were diagnosed to be having ST, according to STIC criteria[21]. Other patients were followed up for the alternate final diagnosis, based on other laboratory investigation findings done by the respective departments. Different aetiologies of fever other than ST were sepsis $(n=17)$, malaria $(n=4)$, enteric fever $(n=4)$, tubercular meningitis $(n=4)$, Japanese encephalitis $(n=3)$, pneumonia $(n=1)$, meningitis $(n=1)$ and dengue $(n=1)$. In few patients $(n=29)$ any diagnosis could not be established as some of them lost follow up due to death before any 
established diagnosis or discharge against advice or non-admission as an outpatient. Diagnostic profile of all the 37 diagnosed ST patients are described here on.

For the screening of scrub typhus cases an easy to do and widely used serological test WeilFelix was performed. For confirming the scrub typhus cases IgM ELISA was used, which is well established and widely performed. Molecular test - Quantitative Real Time PCR is a relatively new, fast and accurate diagnostic modality which is yet to be evaluated. In our study we tried to see the usefulness and utility of Real Time PCR in comparison to a standard methodology for diagnosing scrub typhus - IgM ELISA. Results of all the 3 tests are as follows:

Weil-Felix test: Out of 100 serum samples tested only 14 samples showed high titers against OXK antigen $(\geq 80)$.

Different OXK titers of all the 100 samples are as follows:

Table 1: Different OXK titers

\begin{tabular}{|l|l|}
\hline OXK Titer & No. of samples \\
\hline$<40$ & 78 \\
\hline 40 & 8 \\
\hline 80 & 6 \\
\hline 160 & 4 \\
\hline 320 & 4 \\
\hline
\end{tabular}

IgM ELISA for scrub typhus: Out of 100 serum samples tested, 34 samples turned out to be IgM ELISA positive.

Out of the 14 samples which have shown high OXK titer ( $\geq 80)$, only 12 samples turned out to be IgM ELISA positive. However, out of the 86 OXK negative (Titer $\leq 40$ ) samples, 22 samples were IgM ELISA positive.

Quantitative Real-Time PCR: The real time PCR assay for detection of 56kD gene of scrub typhus was done by Geno Sen's ${ }^{\circledR}$ Scrub Typhus RG quantitative PCR kit (Genome Diagnostics Pvt. Ltd, Solan, Himachal Pradesh, India) which can detect upto (sensitivity) 70 Copies/ml of DNA. Along with detection, quantification of bacterial DNA was also done. Results are as follows:

Out of the 34 IgM ELISA positive samples $24(70.6 \%)$ samples were positive for PCR and out of 20 highly suspected but IgM ELISA negative samples 3 turned out to be PCR 
positive. So, out of 54 samples tested for PCR, 27 (50\%) samples were PCR positive (see Table 2)

Table 2: PCR Results

\begin{tabular}{|l|l|l|l|l|l|l|l|l|}
\hline $\begin{array}{l}\text { SL } \\
\text { No. }\end{array}$ & $\begin{array}{l}\text { Ct } \\
\text { value }\end{array}$ & $\begin{array}{l}\text { DNA } \\
(\text { Copies/ml) }\end{array}$ & $\begin{array}{l}\text { SL } \\
\text { No. }\end{array}$ & $\begin{array}{l}\text { Ct } \\
\text { value }\end{array}$ & $\begin{array}{l}\text { DNA } \\
(\text { Copies/ml })\end{array}$ & $\begin{array}{l}\text { SL } \\
\text { No. }\end{array}$ & $\begin{array}{l}\text { Ct } \\
\text { Value }\end{array}$ & $\begin{array}{l}\text { DNA } \\
(\text { Copies/ml })\end{array}$ \\
\hline 1 & 32.22 & 2647 & 10 & 29.95 & 21242 & 19 & 28.75 & 26838 \\
\hline 2 & 29.75 & 22967 & 11 & 21.17 & 2636982 & 20 & 28.95 & 25201 \\
\hline 3 & 24.67 & 350201 & 12 & 21.22 & 2508248 & 21 & 19.27 & 2704417 \\
\hline 4 & 29.05 & 23650 & 13 & 32.65 & 2312 & 22 & 20.62 & 2687042 \\
\hline 5 & 28.74 & 27005 & 14 & 23.16 & 24862 & 23 & 33.85 & 2634 \\
\hline 6 & 19.11 & 2778621 & 15 & 29.1 & 2214 & 24 & 30.31 & 20612 \\
\hline 7 & 28.9 & 26007 & 16 & 18.14 & 2885302 & 25 & 34.02 & 2562 \\
\hline 8 & 31.85 & 3350 & 17 & 21.81 & 2508248 & 26 & 18.23 & 2839547 \\
\hline 9 & 28.7 & 26635 & 18 & 25.75 & 312215 & 27 & 21.62 & 2397324 \\
\hline
\end{tabular}

Different loads of DNA copies/mL from positive PCR samples were categorized into 4 different categories and correlated with the duration of fever. DNA copies were categorized based on multiplies of 10 (Table).

Very low count - DNA copies in multiplies of $10^{3}$

Low count - DNA copies in multiplies of $10^{4}$

Medium count - DNA copies in multiplies of $10^{5}$

High count - DNA copies in multiplies of $10^{6}$

Table 3: Relation between DNA copies and days of fever when sample was collected

\begin{tabular}{|c|c|c|c|c|}
\hline \multirow[b]{2}{*}{$\begin{array}{l}\text { Days of } \\
\text { Fever }\end{array}$} & \multicolumn{4}{|l|}{ DNA copies/mL } \\
\hline & $\begin{array}{l}\text { Very low } \\
\text { No. of samples }\end{array}$ & $\begin{array}{l}\text { Low } \\
\text { No. of samples }\end{array}$ & $\begin{array}{l}\text { Medium } \\
\text { No. of samples }\end{array}$ & $\begin{array}{l}\text { High } \\
\text { No. of samples }\end{array}$ \\
\hline$<7$ days & 4 & 6 & 2 & 9 \\
\hline 8-14 days & 2 & 4 & 0 & 0 \\
\hline
\end{tabular}


Relation between different bacterial DNA loads and day of fever when sample was collected were analysed which was statistically not significant (see Table 4).

Table 4: Relation between Days of fever and no. of bacterial DNA copies/ml

\begin{tabular}{||l||l||}
\hline Chi-squared & 5.400 \\
\hline \hline DF (Degree of Freedom) & 3 \\
\hline \hline Significance level & $\mathrm{P}=0.1447$ \\
\hline \hline Contingency coefficient & 0.408 \\
\hline
\end{tabular}

Fig. 1: Application plot for Real Time PCR assay (X-axis: No. of cycles, Y-axis: Normalized fluorescence, S1- standard 1, S2-satandard 2, S3-standard 3, S4-standard 4, S5standard 5, NC- Negative control, NS- Negative serum sample, ST 15-Positive serum sample)

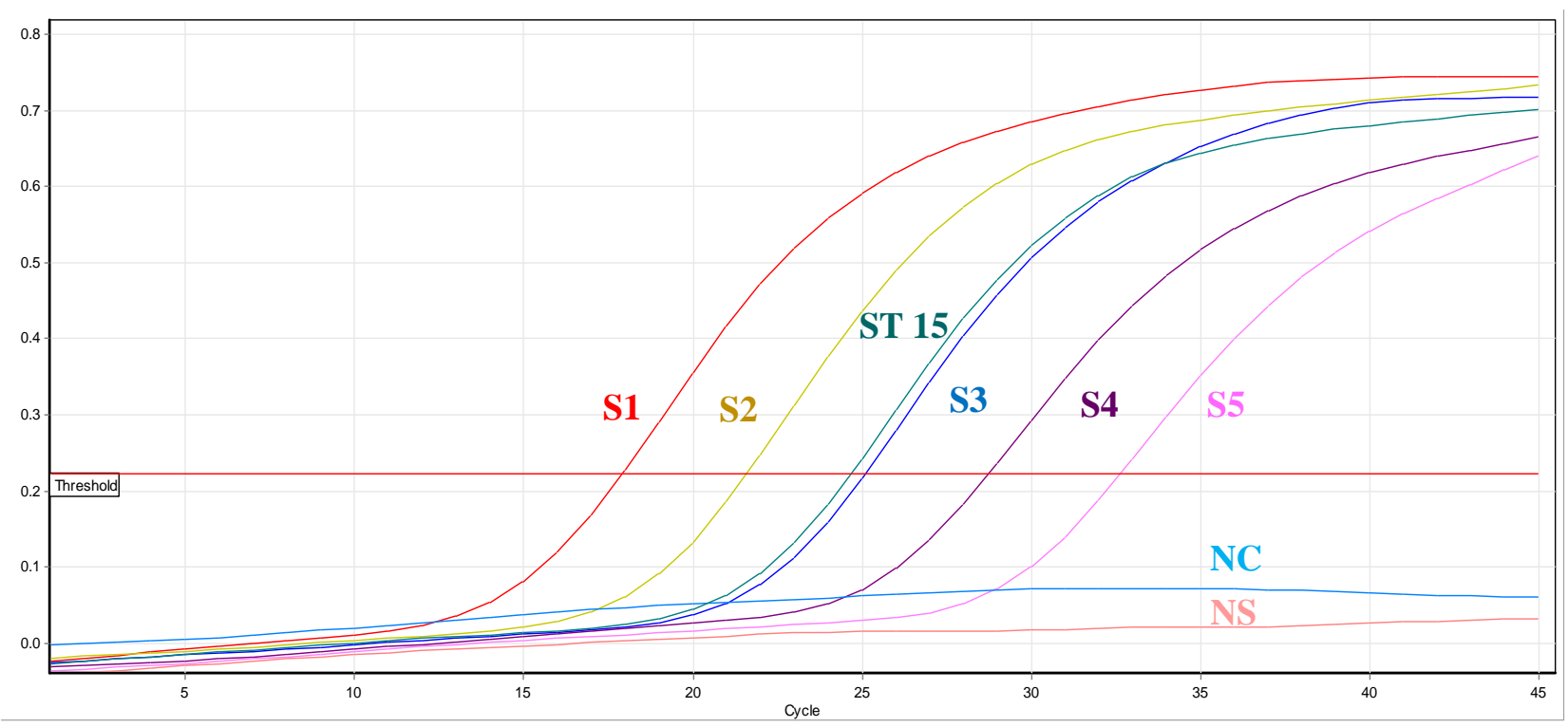


Fig. 2: Application plot for Real Time PCR assay (X-axis: No. of cycles, Y-axis: Normalized fluorescence, S1- standard 1, S2-satandard 2, S3-standard 3, S4-standard 4, S5-standard 5, NCNegative control, NS- Negative serum sample, ST 52-Positive serum

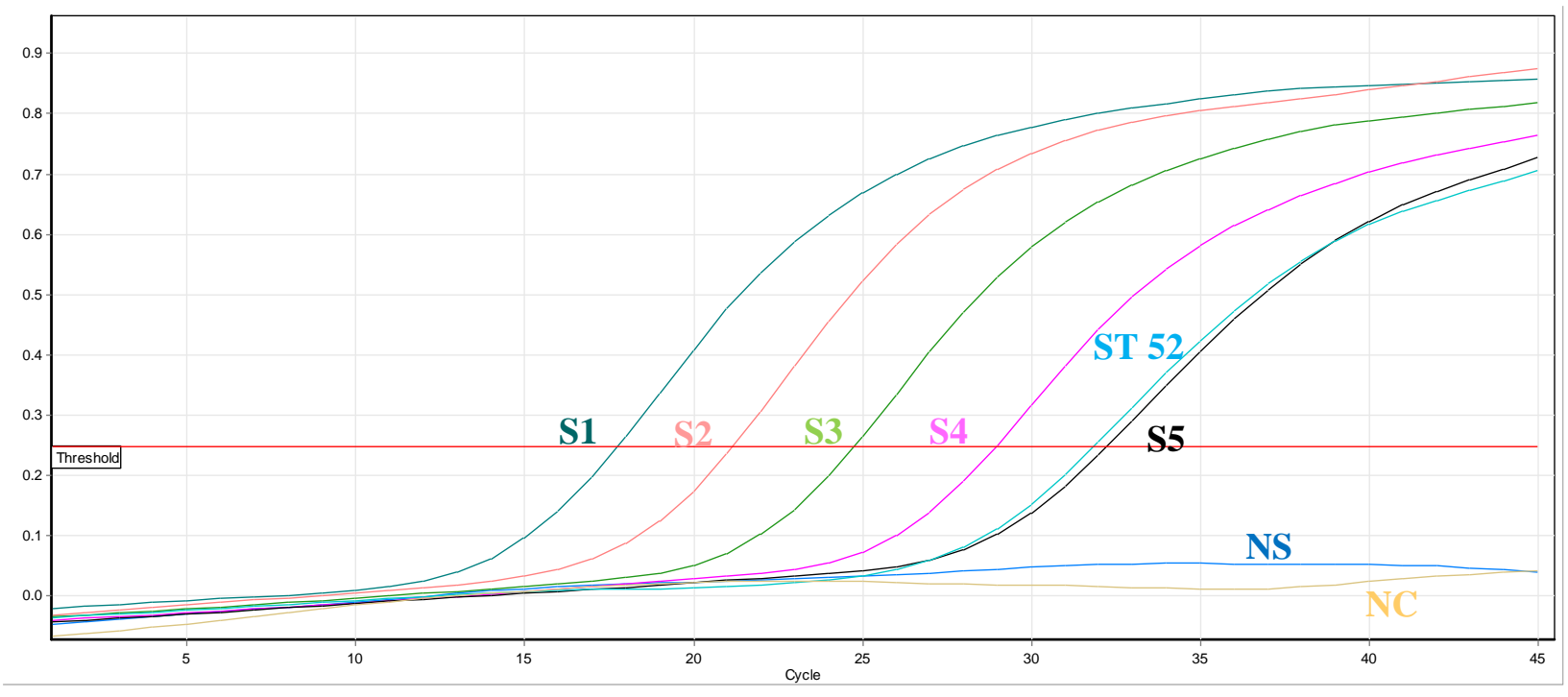

Taking IgM ELISA as the standard methodology for diagnosing scrub typhus both the screening test - Weil-Felix and Real-time PCR test results were compared and analysed statistically by using different tools. Results are as follows:

Table 5: Diagnostic accuracy of Weil-Felix and PCR in comparison to IgM ELISA

\begin{tabular}{|l|l|l|l|l|l|l|l|}
\hline $\begin{array}{l}\text { Diagnostic } \\
\text { tests }\end{array}$ & Sensitivity & Specificity & $\begin{array}{l}\text { 95\% } \\
\text { Confidence } \\
\text { Interval }\end{array}$ & $\begin{array}{l}\text { Positive } \\
\text { Predictive } \\
\text { value }\end{array}$ & $\begin{array}{l}\text { Negative } \\
\text { Predictive } \\
\text { value }\end{array}$ & $\begin{array}{l}\text { Positive } \\
\text { likelihood } \\
\text { ratio }\end{array}$ & $\begin{array}{l}\text { Negative } \\
\text { likelihood } \\
\text { ratio }\end{array}$ \\
\hline $\begin{array}{l}\text { Weil } \\
\text { Felix }\end{array}$ & $35.3 \%$ & $96.9 \%$ & $0.56-0.75$ & $85.71 \%$ & $74.42 \%$ & 11.65 & 0.67 \\
\hline PCR & $70.59 \%$ & $95.45 \%$ & $0.74-0.89$ & $88.89 \%$ & $86.3 \%$ & 15.53 & 0.31 \\
\hline
\end{tabular}

\section{DISCUSSION}

Scrub typhus is one of the most important cause of acute febrile illness, taking toll of lot of lives mainly due to its initial vague presentations but serious complications, if remains undiagnosed and not treated on time. Different aetiologies of acute febrile illness cases like malaria, dengue, leptospirosis, scrub typhus, typhoid fever, Japanese encephalitis and influenza 
have been mentioned in various literatures[22,23]. Being in an endemic zone, scrub typhus is very much prevalent in India, causing multiple outbreaks every year[24,25], especially in the North-Eastern part of the country[13,14,26,27]. Scrub typhus is a well-known disease in the state of Meghalaya, which has a local name also "Niangsohot". Every year lots of cases and deaths due to scrub typhus are being reported from Meghalaya and it has become an important cause of acute febrile illness and related mortality and morbidity. Most of the time the disease remains undiagnosed due to non-specific clinical presentation and low index of suspicion among physicians. Regarding diagnosis, the most widely used screening test Weil-Felix suffers lack of sensitivity and specificity, whereas gold standard test IFA lacks in standardization and availability. Presently many studies and case reports on scrub typhus are coming out from different parts of the country, revealing new pockets and true scenario of this dreaded disease. PCR as a molecular test scores more in the aspect of sensitivity and specificity but warrants more stringent conditions. Till now most of the studies have used Nested PCR, which has shown good sensitivity and specificity but currently Real-Time PCR is on the trends with a boon of quantification.

This study was a venture to know different aetiologies of acute febrile illness and to evaluate Real-Time Quantitative PCR as an accurate, less labour intensive and with an extra benefit of quantification; for diagnosing an important cause of acute febrile illness - Scrub Typhus.

\section{Aetiologies of AFI}

One hundred patients of acute febrile illness cases were evaluated, out of which 37 were diagnosed as scrub typhus. This result is comparable with a study by Chrispal et al., where $47.5 \%$ cases of acute febrile illness cases were scrub typhus positive[23]. In other studies by Jamil et al.,61 and 113 cases of Scrub Typhus were reported from NEIGRIHMS during 2013 and 2014 respectively[13,14], which also supports the high prevalence of scrub typhus in this region.

Regarding other causes of AFI, Sepsis (17 cases), Enteric fever (4 cases), Malaria (4 cases), JE (3 cases), TBM (3 cases), Pneumonia (1 case), Meningitis (1 case), Dengue (1 case) were diagnosed.

Unfortunately, the final diagnosis of 29 non scrub typhus patients could not be traced as 21 of them were OPD patients. For others ( 8 patients) final diagnosis could not be arrived due to limitations of available diagnostic modalities or early discharge against medical advice. 


\section{Diagnostic profile}

Weil-Felix test - In our study only $14 \%$ patients had positive OXK titer of $\geq 80$. Considering this titer of $\geq 80$ we found that, the sensitivity of the test is only $35.29 \%$ and specificity of 96.97\%. Weil-Felix test has shown positive predictive value of $85.7 \%$ and negative predictive value of $74.42 \%$. Positive Likelihood Ratio for Weil-Felix test was 11.647 and Negative Likelihood Ratio was 0.667.

In a study by Prakash et al. Weil-Felix test has shown higher rates of positivity of $28.7 \%$, sensitivity of $59 \%$ and similar specificity of $94 \%$ when cutoff titer of $\geq 80$ was used[28].

Another study by Anitha et al. has reported sensitivity of Weil-Felix as $81.34 \%, 65.67 \%$, and $50.38 \%$, whereas specificity of 70.93\%, 94.19\%, 95.51\% with OXK titers of 80, 160 and 320, respectively[29].

From the diagnostic point of view scrub typhus will always be a challenging task, because of its divergent presentations and scope of clinical misjudgement. In a resource poor set up like India, especially in the corner most part of the country - the north-eastern region, easy to do and cheaper ways of diagnostics will always be more preferred. Therefore, in an endemic zone of scrub typhus Weil-Felix will be a preferred tool for screening and its results can be confirmed by serological tools like IgM ELISA or Molecular tests like Real-time PCR. Sensitivity, which is the parameter of choice to know the performance of a test, suffers a lot, if high cut off titers of antibodies against OXK is used. Therefore, seroprevalence of scrub typhus and thereby determining the cut off titer for OXK is especially important. Moreover, Weil-Felix has a good PPV and NPV despite having low sensitivity as shown in our study. So, it remains as a good tool for the screening of scrub typhus, especially in our set up.

IgM ELISA test - As Immunoflourescence assay (IFA) - the gold standard test for scrub typhus, was not available and moreover its lack of standardization worldwide[19], IgM ELISA was considered as the standard methodology test in our study. All the 34 positive samples by IgM ELISA were true positive samples and were used to compare the results of the other 2 tests.

In a recent study to evaluate diagnostic accuracy of the InBios Scrub Typhus Detect ELISA kit for the detection of IgM Antibodies by Blacksell et al., which was also used in our study, a sensitivity of $93 \%$ and specificity of $91 \%$ was reported when cut off OD value for IgM ELISA was calculated according to manufacturer's instructions[30]. 
Jang et al., evaluated IgM ELISA for the diagnosis of scrub typhus and reported sensitivity of $100 \%$ and specificity of $99 \%$ for IgM IFA-positive samples[31]. The performance and diagnostic accuracy of this IgM ELISA kit was validated by different authors in India [29,3236] and the results were quite satisfactory. Even though IFA is the gold standard test for diagnosing scrub typhus, it is difficult to perform, cumbersome, requires a skilled observer, mandates inclusion of several antigenic types, subjective, and too expensive to be imported[36]. The sensitivity and specificity of ST IgM ELISA are almost equivalent to those of IFA, and it can be performed by most laboratories[18,37]. Therefore for confirmation of the screening positive samples IgM ELISA is a very good alternative to IFA.

However, few false positive results were obtained by Prakash et al., in patients with falciparum malaria, pulmonary tuberculosis, Streptococcus viridans septicaemia, and typhoid fever[33]. But we in our study did not get any such instances of cross reactivity.

Real Time PCR assay - Total 27 samples were positive for Orientia DNA by using RealTime Quantitative PCR assay. Out of 27 samples 24 were IgM ELISA positive whereas 3 samples were ELISA negative. Regarding Weil-Felix test, amongst the 27 PCR positive samples 16 samples were OXK negative.

When Real-time PCR results were analysed statistically, it has shown sensitivity of $70.59 \%$, specificity of $95.45 \%$, positive predictive value of $88.89 \%$ and negative predictive value of $86.3 \%$. It has also shown positive likelihood ratio of 15.529 and negative likelihood ratio of 0.308 .

In a similar study by Anitharaj et al., evaluation of the same real-time PCR kit was done which was used in our study. In that study 49(38.8\%) samples were positive out of 126 samples tested. Out of 77 ELISA positive samples 42 (54.54\%) were PCR positive. In that study the sample of choice was buffy coat and IgM ELISA was used as an alternative to IFA for serological confirmation, which was like our study[38].

Difference between positivity rates amongst both the studies can be attributed to the different prevalence rates of the study location.

In another study by Singhsilarak et al. 17 (62.9\%) samples were positive by quantitative realtime PCR out of 27 samples, confirmed serologically by IgM ELISA, which is like our findings[39]. 
Another study was done by Bakshi et al., to develop a qualitative real-time PCR targeting $56 \mathrm{kDa}$ gene. In that study $73 \%$ samples turned out to be PCR positive amongst the clinically suspected and OXK positive (cut off titer $\geq 160$ ) serum samples[40].

In a study by Usha et al., 34.69\% patients were nested PCR positive targeting 56kDa gene[41]. A study by Mahajan et al. where eschar samples were collected from 3 regions of the country in which $79.5 \%$ of positive samples for 56kDa gene using conventional PCR were reported[42].

Molecular diagnosis always takes the upper hand from serological tests, as using PCR tests Orientia DNA can be detected accurately and within the 1st week of infection before the appearance of antibodies in the human blood. Over the year's different types of PCR assays like conventional, nested, qualitative real-time PCR assays were tried and evaluated for the diagnosis of scrub typhus. Recently quantitative real-time PCR kits are being used in India, "Geno-Sen's Scrub Typhus (Rotor Gene) real time PCR kit" is one of those. The target gene in this kit is $56-\mathrm{kDa}$, which is the most common targeted gene. According to the manufacturers, specificity of the kit is $100 \%$ and sensitivity is remarkably high too, having the ability to detect DNA load of as low as only 70 copies/mL. The kit's technical brochure also mentions that gene sequence analysis of the amplified region of ST shows a pronounced homology among the various ST subtypes, and no homology with other DNA. No homology was found with RNA and DNA from different viruses and bacteria too as they did not show any positive signal with this kit.

In our study 10 IgM ELISA positive samples were PCR negative. These 10 samples cannot be ignored as false ELISA positive, as detection of $56 \mathrm{kDa}$ gene depends on the duration of febrile illness at the time of blood collection and samples used. Eschar samples are found to be yielding better results for PCR[42]. Usually, ST-qPCR gives positive results within the 1st week of the acute illness, whereas IgM antibody starts appearing from day 7 onwards. In our study 21(77.8\%) out of 27 PCR samples were collected within the 1 st 7 days of illness rest other 6 samples were obtained in the 2 nd week of illness. According to Saisongkorh et al., ST-PCR positivity was observed up to day 22 in some patients[43]. Compared to other types of PCR, real-time PCR using the above-mentioned kit is faster - results can be obtained within 2 hours. Another advantage of quantitative real time PCR is its quality of quantification. This added advantage can be utilized for knowing the disease severity and treatment follow-up. Being a test with good sensitivity and specificity and better PPV and NPV values, qPCR can be used as a particularly good confirmatory test. Though cost effectiveness and requirement of stringent 
conditions for sample processing and testing, makes this test unacceptable to be used as a routine test.

Limitations of the study - i) Other than serum samples buffy coats, blood clots or eschar samples could have been used for DNA extraction to get a better yield of extracted DNA. ii) Only one gene was targeted in the used PCR kit, whereas other 2 genes, namely $47 \mathrm{kDa}$ and groEL genes were not considered. This can be related with the lower sensitivity when compared with IgM ELISA positive samples. iii) ST IFA test was not done which is considered to be the "Gold Standard" test for diagnosing scrub typhus. This can be attributed to the lack of availability of the IFA kit in India and lack of complete evaluation. Moreover, technical glitch and subjectivity of reporter's observation makes it difficult to perform and restricts its usefulness. iv) PCR results could have been better, if all the samples could have been collected on the 1st week of illness. Although, it has not shown any statistical significance in our study but there is always a higher chance of better yield of bacterial DNA before the appearance of antibodies.

\section{SUMMARY}

This study was conducted to determine various aetiologies of febrile illness cases and to evaluate real-time PCR assay for diagnosing one of the important causes of febrile illness in this part of the country - scrub typhus. The study was done in the Department of Microbiology, NEIGRIHMS, a tertiary care hospital of North-Eastern India, during the study period of 1 year from June 2016 to May 2017. Out of the 100 patients evaluated for febrile illness 37 patients were diagnosed as a case of scrub typhus based on initial screening by Weil-Felix test and confirmation by IgM ELISA and Real-time quantitative PCR. Other aetiologies of febrile illness like Sepsis, Malaria, JE, TBM, Meningitis and Pneumonia were also found in our study. While performing screening for scrub typhus by using Weil-Felix test 14 out of 100 patients showed high titers $(\geq 80)$ of antibodies against OXK antigen. IgM ELISA was done for all the 100 patient samples in which 34 samples have shown positive results. In our study we have standardized and evaluated the performance of a newly available quantitative real time PCR kit - “Geno-Sen's Scrub Typhus (Rotor Gene) real time PCR kit”. This kit targets 56kDa major outer membrane protein gene of scrub typhus. It has shown satisfactory results. 24 out of 34 IgM ELISA positive samples and 3 out of 20 IgM ELISA negative samples have shown 
PCR positive results. Taking IgM ELISA as a standard methodology for diagnosing scrub typhus we have analysed the performance of Weil-Felix and real-time PCR tests in comparison to IgM ELISA. Considering $\geq 80$ as a cut off titer, Weil-Felix test has shown sensitivity of $35.29 \%$, specificity of $96.97 \%$, PPV of $85.7 \%$ and NPV of $74.42 \%$. Real-time PCR has shown sensitivity of $70.59 \%$, specificity of $95.45 \%$, PPV of $88.89 \%$ and NPV of $86.3 \%$. Even though Weil-Felix has shown low sensitivity in our study, considering its good PPV and NPV we can use this test as screening tool of scrub typhus in a resource poor setup. But cut off titer for antibody against OXK should be re-evaluated in this geographical area based on the prevalence of scrub typhus cases. The newly available Real-time PCR kit can be used as a confirmation tool for scrub typhus, but its performance can be re-evaluated using other patient samples like buffy coat, blood clot or eschar tissues.

\section{CONCLUSION}

Scrub typhus being a diagnostic challenge to the clinicians as well as to the clinical microbiologists, will always continue to raise questions regarding its correct, accurate and faster diagnostic approach. Even though its treatment is plain sailing, provided diagnosed on time. But situations may turn out to be detrimental for the patients if determination of the correct one is delayed. In this purpose accurate and cost-effective screening along with flawless confirmation can lead us to the desired outcome for the patients.

In a place like North-East of India, Weil-Felix can still serve the purpose of screening out the cases of scrub typhus but for confirmation IgM ELISA or Real-Time PCR can be used. If we can combine the power of both the tests then there will be less chances of missing a case.

The performance of the commercial quantitative real-time PCR kit used in our study is satisfactory. Molecular diagnosis should be carried out preferably during the $1^{\text {st }}$ week of febrile illness for better results. Due to the reasonable levels of sensitivity and specificity of Real-time PCR, its continued usage as a standard methodology in developing countries like India may be a good choice, as utility and availability of IFA kits are still questionable and culturing Orientia is a tough nut to crack.

\section{REFERENCES}

1. Traub, R.; Wisseman, C.L. Ecological considerations in scrub typhus. Bull World Health Organ 1968, 39, 219-230.

2. Sachdeva Scrub typhus: An under diagnosed re-emerging zoonotic disease Available online: http://www.tjmrjournal.org/article.asp?issn=1119- 
0388; year $=2014 ;$ volume $=17 ;$ issue $=2 ;$ spage $=133$; epage $=136$; aulast $=$ Sachdeva $\quad$ (accessed on Aug 29, 2017).

3. WHO | WHO recommended surveillance standards, Second edition Available online: http://www.who.int/csr/resources/publications/surveillance/WHO_CDS_CSR_ISR_99_ 2_EN/en/ (accessed on Aug 29, 2017).

4. Luce-Fedrow, A.; Lehman, M.L.; Kelly, D.J.; Mullins, K.; Maina, A.N.; Stewart, R.L.; Ge, H.; John, H.St.; Jiang, J.; Richards, A.L. A Review of Scrub Typhus (Orientia tsutsugamushi and Related Organisms): Then, Now, and Tomorrow. Trop Med Infect Dis 2018, 3, doi:10.3390/tropicalmed3010008.

5. Endemic Scrub Typhus in South America | NEJM Available online: https://www.nejm.org/doi/10.1056/NEJMoa1603657?url_ver=Z39.88-

2003\&rfr_id=ori:rid:crossref.org\&rfr_dat=cr_pub\%3dwww.ncbi.nlm.nih.gov (accessed on Jan 5, 2020).

6. Kocher, C.; Jiang, J.; Morrison, A.C.; Castillo, R.; Leguia, M.; Loyola, S.; Ampuero, J.S.; Cespedes, M.; Halsey, E.S.; Bausch, D.G.; et al. Serologic Evidence of Scrub Typhus in the Peruvian Amazon. Emerg. Infect. Dis. 2017, 23, 1389-1391, doi:10.3201/eid2308.170050.

7. Vivekanandan, M.; Mani, A.; Priya, Y.S.; Singh, A.P.; Jayakumar, S.; Purty, S. Outbreak of scrub typhus in Pondicherry. J Assoc Physicians India 2010, 58, 24-28.

8. Siraj Ahmed Khan Re-emergence of scrub typhus in northeast India. International Journal of Infectious Diseases 2012, 16, 889-890.

9. Tilak, R.; Wankhade, U.; Kunwar, R.; Tilak, V. Emergence of Schoengastiella ligula as the vector of scrub typhus outbreak in Darjeeling: Has Leptotrombidium deliense been replaced? Indian Journal of Public Health 2011, 55, 92, doi:10.4103/0019-557X.85239.

10. M. Chauhan; S. Mahajan; Manish S Scrub typhus: An emerging scourge. Indian Journal of Basic and Applied Medical Research 2015, 4, 394-401.

11. Sankhyan, N.; Saptharishi, L.G.; Sasidaran, K.; Kanga, A.; Singhi, S.C. Clinical profile of scrub typhus in children and its association with hemophagocytic lymphohistiocytosis. Indian Pediatr 2014, 51, 651-653.

12. Watt, G.; Jongsakul, K.; Suttinont, C. POSSIBLE SCRUB TYPHUS COINFECTIONS IN THAI AGRICULTURAL WORKERS HOSPITALIZED WITH LEPTOSPIROSIS. The American Journal of Tropical Medicine and Hygiene 2003, 68, 89-91, doi:10.4269/ajtmh.2003.68.89.

13. Jamil, M.; Lyngrah, K.G.; Lyngdoh, M.; Hussain, M. Clinical Manifestations and Complications of Scrub Typhus: A Hospital Based Study from North Eastern India. $J$ Assoc Physicians India 2014, 62, 19-23.

14. Jamil, M.D.; Hussain, M.; Lyngdoh, M.; Sharma, S.; Barman, B.; Bhattacharya, P.K. Scrub typhus meningoencephalitis, a diagnostic challenge for clinicians: A hospital based study from North-East India. Journal of Neurosciences in Rural Practice 2015, 6, 488, doi:10.4103/0976-3147.169769.

15. Md. Jamil; KG Lyngrah Journal of the association of physicians of india 2014, 62, 1923.

16. Mahajan, S.K. Rickettsial diseases. J Assoc Physicians India 2012, 60, 37-44.

17. Rathi, N.B.; Rathi, A.N.; Goodman, M.H.; Aghai, Z.H. Rickettsial diseases in central India: proposed clinical scoring system for early detection of spotted fever. Indian Pediatr 2011, 48, 867-872.

18. La Scola, B.; Raoult, D. Laboratory diagnosis of rickettsioses: current approaches to diagnosis of old and new rickettsial diseases. J Clin Microbiol 1997, 35, 2715-2727.

19. Blacksell, S.D.; Bryant, N.J.; Paris, D.H.; Doust, J.A.; Sakoda, Y.; Day, N.P.J. Scrub typhus serologic testing with the indirect immunofluorescence method as a diagnostic 
gold standard: a lack of consensus leads to a lot of confusion. Clin. Infect. Dis. 2007, 44, 391-401, doi:10.1086/510585.

20. Fournier, P.-E.; Raoult, D. Suicide PCR on Skin Biopsy Specimens for Diagnosis of Rickettsioses. J Clin Microbiol 2004, 42, 3428-3434, doi:10.1128/JCM.42.8.34283434.2004.

21. Paris, D.H.; Blacksell, S.D.; Nawtaisong, P.; Jenjaroen, K.; Teeraratkul, A.; Chierakul, W.; Wuthiekanun, V.; Kantipong, P.; Day, N.P.J. Diagnostic Accuracy of a LoopMediated Isothermal PCR Assay for Detection of Orientia tsutsugamushi during Acute Scrub Typhus Infection. PLoS Negl Trop Dis 2011, 5, doi:10.1371/journal.pntd.0001307.

22. Rajneesh Joshi; SP Kalantri Acute Undifferentiated Fever: Management Algorithm. In Update on Tropical Fever; Association of Physicians of India, 2015.

23. Chrispal, A.; Boorugu, H.; Gopinath, K.G.; Chandy, S.; Prakash, J.A.J.; Thomas, E.M.; Abraham, A.M.; Abraham, O.C.; Thomas, K. Acute undifferentiated febrile illness in adult hospitalized patients: the disease spectrum and diagnostic predictors - an experience from a tertiary care hospital in South India. Trop Doct 2010, 40, 230-234, doi:10.1258/td.2010.100132.

24. Laskar, A.R.; Suri, S.; Acharya, A.S. Scrub Typhus: Re-emerging Public Health Problem in India. Journal of Communicable Diseases 2015, 47, 19-25.

25. Annual Report $2014-152016$.

26. Singh, S.I.; Devi, K.P.; Tilotama, R.; Ningombam, S.; Gopalkrishna, Y.; Singh, T.B.; Murhekar, M.V. An outbreak of scrub typhus in Bishnupur district of Manipur, India, 2007. Trop Doct 2010, 40, 169-170, doi:10.1258/td.2010.090468.

27. Dass, R.; Deka, N.M.; Duwarah, S.G.; Barman, H.; Hoque, R.; Mili, D.; Barthakur, D. Characteristics of Pediatric Scrub Typhus during an Outbreak in the North Eastern Region of India: Peculiarities in Clinical Presentation, Laboratory Findings and Complications. Indian J Pediatr 2011, 78, 1365-1370, doi:10.1007/s12098-011-0470-5.

28. Prakash, J. a. J.; Kavitha, M.L.; Mathai, E. Nested polymerase chain reaction on blood clots for gene encoding $56 \mathrm{kDa}$ antigen and serology for the diagnosis of scrub typhus. Indian Journal of Medical Microbiology 2011, 29, 47, doi:10.4103/0255-0857.76524.

29. Anitharaj, V.; Stephen, S.; Pradeep, J.; Park, S.; Kim, S.-H.; Kim, Y.J.; Kim, E.-Y.; Kim, Y.-W. Serological Diagnosis of Acute Scrub Typhus in Southern India: Evaluation of InBios Scrub Typhus Detect IgM Rapid Test and Comparison with other Serological Tests. J Clin Diagn Res 2016, 10, DC07-DC10, doi:10.7860/JCDR/2016/24051.8861.

30. Blacksell, S.D.; Tanganuchitcharnchai, A.; Nawtaisong, P.; Kantipong, P.; Laongnualpanich, A.; Day, N.P.J.; Paris, D.H. Diagnostic Accuracy of the InBios Scrub Typhus Detect Enzyme-Linked Immunoassay for the Detection of IgM Antibodies in Northern Thailand. Clin Vaccine Immunol 2016, 23, 148-154, doi:10.1128/CVI.0055315 .

31. Jang, W.-J.; Huh, M.-S.; Park, K.-H.; Choi, M.-S.; Kim, I.-S. Evaluation of an Immunoglobulin M Capture Enzyme-Linked Immunosorbent Assay for Diagnosis of Orientia tsutsugamushi Infection. Clin Diagn Lab Immunol 2003, 10, 394-398, doi:10.1128/CDLI.10.3.394-398.2003.

32. Mathai, E.; Rolain, J.M.; Verghese, G.M.; Abraham, O.C.; Mathai, D.; Mathai, M.; Raoult, D. Outbreak of Scrub Typhus in Southern India during the Cooler Months. Annals of the New York Academy of Sciences 2003, 990, 359-364, doi:10.1111/j.17496632.2003.tb07391.x.

33. Prakash, J. a. J.; Abraham, O.C.; Mathai, E. Evaluation of tests for serological diagnosis of scrub typhus. Trop Doct 2006, 36, 212-213, doi:10.1258/004947506778604715. 
34. Narvencar, K.P.S.; Rodrigues, S.; Nevrekar, R.P.; Dias, L.; Dias, A.; Vaz, M.; Gomes, E. Scrub typhus in patients reporting with acute febrile illness at a tertiary health care institution in Goa. Indian J Med Res 2012, 136, 1020-1024.

35. Isaac, R.; Varghese, G.M.; Mathai, E.; J, M.; Joseph, I. Scrub typhus: prevalence and diagnostic issues in rural Southern India. Clin. Infect. Dis. 2004, 39, 1395-1396, doi: $10.1086 / 424748$.

36. Stephen, S.; Kandhakumari, G.; Pradeep, J.; Vinithra, S.M.; Siva, P.K.; Hanifah, M.; Vanithadevi, E. Scrub typhus in South India: a re-emerging infectious disease. Jpn. J. Infect. Dis. 2013, 66, 552-554.

37. Coleman, R.E.; Sangkasuwan, V.; Suwanabun, N.; Eamsila, C.; Mungviriya, S.; Devine, P.; Richards, A.L.; Rowland, D.; Ching, W.-M.; Sattabongkot, J.; et al. Comparative evaluation of selected diagnostic assays for the detection of $\operatorname{IgG}$ and $\operatorname{IgM}$ antibody to Orientia tsutsugamushi in Thailand. Am. J. Trop. Med. Hyg. 2002, 67, 497-503.

38. Anitharaj, V.; Stephen, S.; Pradeep, J.; Pooja, P.; Preethi, S. Validation of Geno-Sen's scrub typhus real time polymerase chain reaction kit by its comparison with a serological ELISA Test. Journal of Global Infectious Diseases 2017, 9, 108, doi:10.4103/jgid.jgid_158_16.

39. Singhsilarak, T.; Leowattana, W.; Looareesuwan, S.; Wongchotigul, V.; Jiang, J.; Richards, A.L.; Watt, G. Short report: detection of Orientia tsutsugamushi in clinical samples by quantitative real-time polymerase chain reaction. Am. J. Trop. Med. Hyg. 2005, 72, 640-641.

40. Bakshi, D.; Singhal, P.; Mahajan, S.K.; Subramaniam, P.; Tuteja, U.; Batra, H.V. Development of a real-time PCR assay for the diagnosis of scrub typhus cases in India and evidence of the prevalence of new genotype of O. tsutsugamushi. Acta Tropica 2007, 104, 63-71, doi:10.1016/j.actatropica.2007.07.013.

41. Usha, K.; Kumar, E.; Kalawat, U.; Kumar, B.S.; Chaudhury, A.; Gopal, D.V.R.S. Molecular characterization of Orientia tsutsugamushi serotypes causing scrub typhus outbreak in southern region of Andhra Pradesh, India. Indian J Med Res 2016, 144, 597603, doi:10.4103/0971-5916.200886.

42. Varghese, G.M.; Janardhanan, J.; Mahajan, S.K.; Tariang, D.; Trowbridge, P.; Prakash, J.A.J.; David, T.; Sathendra, S.; Abraham, O.C. Molecular Epidemiology and Genetic Diversity of Orientia tsutsugamushi from Patients with Scrub Typhus in 3 Regions of India. Emerging Infectious Diseases 2015, 21, 64-69, doi:10.3201/eid2101.140580.

43. Saisongkorh, W.; Chenchittikul, M.; Silpapojakul, K. Evaluation of nested PCR for the diagnosis of scrub typhus among patients with acute pyrexia of unknown origin. Trans $R$ Soc Trop Med Hyg 2004, 98, 360-366, doi:10.1016/j.trstmh.2003.10.012. 